\title{
Leveraging Lean Production Philosophy for Rationalising a Non-Linear Representation of Construction Specifications
}

\author{
Erezi Utiome $^{1}$ and Robin Drogemuller ${ }^{2}$
}

\begin{abstract}
This paper presents an approach, based on Lean production philosophy, for rationalising the processes involved in the production of specification documents for construction projects. Current construction literature erroneously depicts the process for the creation of construction specifications as a linear one. This traditional understanding of the specification process often culminates in process-wastes. On the contrary, the evidence suggests that though generalised, the activities involved in producing specification documents are nonlinear.

Drawing on the outcome of participant observation, this paper presents an optimised approach for representing construction specifications. Consequently, the actors typically involved in producing specification documents are identified, the processes suitable for automation are highlighted and the central role of tacit knowledge is integrated into a conceptual template of construction specifications. By applying the transformation, flow, value (TFV) theory of Lean production the paper argues that value creation can be realised by eliminating the wastes associated with the traditional preparation of specification documents with a view to integrating specifications in digital models such as Building Information Models (BIM). Therefore, the paper presents an approach for rationalising the TFV theory as a method for optimising current approaches for generating construction specifications based on a revised specification writing model.
\end{abstract}

Keywords: construction projects, construction specifications, lean philosophy, tfv theory.

\section{Introduction}

Construction specifications are the written representations of the quality of materials and associated workmanship recommended in the production of those products/materials. Information from specifications are crucial for project planning and management and are valuable in the roles they perform, such as: in construction documentation, bidding, and as parts of contract documents (Goldbloom, 1992; Kalin, Weygant, Rosen, \& Regener, 2010). As a result, over the years, specification documents have drawn a significant level of attention. However, the factors underpinning their production have not been sufficiently investigated (Hartman, 2001; Kalin et al., 2010).

Detailed research by (Emmitt (2001), 2006)) into their complexity show that the decision-making processes which underlie the specification of building products is an important aspect of construction often taken for granted. Although the investigation by Emmitt (2001) focused on the influence of environmental factors in the specification of new

$1 \quad$ Researcher, School of Civil Engineering and Built Environment, Queensland University of Technology (QUT), 2 George Street Brisbane, Queensland, Tel: +61-7-3138-4503, E-mail: e.utiome@qut.edu.au.

2 Professor, School of Design and School of Civil Engineering and Built Environment, Queensland University of Technology (QUT), 2 George Street Brisbane, Queensland, Tel: +61-7-3138-6965, E-mail: robin.drogemuller@qut.edu.au. 
building products, its outcomes can be tailored and extended to other aspects of construction specifications.

Lean thinking, on the other hand, is a user-centred process for eliminating waste in pursuit of value creation and optimisation (Oppenheim, Murman, \& Secor, 2011). The Lean concept originates from the manufacturing industry and is valued as an improvement on the generic theory of production and construction. It argues that production can be viewed from the three, complementary, interdependent perspectives of Transformation, Flow and Value (Bertelsen \& Koskela, 2002; Koskela, 2000b). Koskela (2000) presents a Transformation, Flow, Value (TFV) theory of production, and by extension, of construction which submits that:

- as a process of transformation, production is conceptualised as a series of tasks aimed at converting inputs to outputs

- as a flow, production is considered from a waste reduction/elimination stand point with a view to cutting off all waste processes through continuous flow and iterative improvements

- from the value perspective, the production process is regarded as the means for achieving value creation in identifying customers' needs, building appropriate solutions and creating products according to specifications which meet the identified needs

Therefore, this research reasons that, similar to the definition of production through the TPV theory of Lean, the production of construction specifications can be rationalised as a process for transforming, producing and creating value for construction information.

\section{Methodology}

\section{Ethnography}

Previous studies have established the validity of the ethnographic participant observation technique in generating data relating to construction specification (Emmitt, 2001). In the context of this research, observation is a methodological investigation of the attributes characteristic of the environment under study (Marshall \& Rossman, 1989). Specifically therefore, participant observation enhances research by ensuring the researcher studies a participant and gets embedded in the activity under study in order to generate the context for subsequent interviews (DeWalt \& DeWalt, 2010).

Thus, by agreement with the Specifier, the primary author made observations of the act of specification. The Specifier under observation was a registered and established Architect whose functional roles had, overtime, extended to the preparation of Specification documents for projects undertaken across the organisation. The results of the observation exercise were captured and have been illustrated in Figure 1 and Figure 2. Participant observation resulted in a workflow diagram of the specification writing process (Figure 1) with the aid of a diagramming software - EdrawSoft (Singh-Gill, 2012).

\section{Transformation}

Following the workflow diagramming, the Specifier was consulted to critique the developed workflow diagram with a view to ascertaining its accuracy. The result of the critique was an encoded, revised representation (see Figure 2 for the codes and their interpretation) which had been streamlined from 14 to 12 constituent parts (due to removal of parameters 5 and 6) with the following additional outcomes:

- Swapping of 1 and 2

- Slightly more detailed description of the specification writing process.

- Addition of Actors 
- Codes were developed for the actors as shown in Figure 2.

$\bullet$

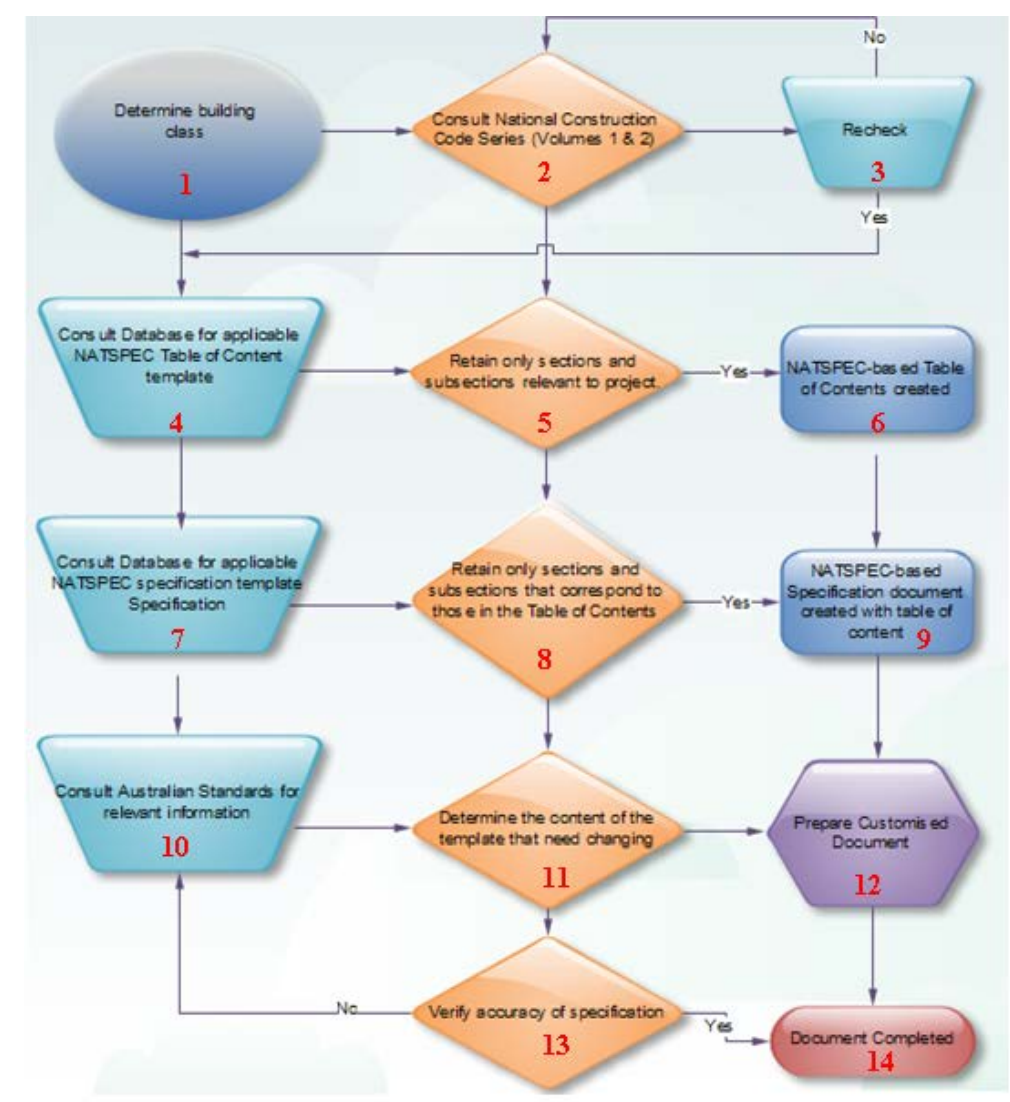

Figure 1. Workflow for the creation of traditional specifications. Note: Each component was manually coded (1-14) in order to track any changes upon review with the Specifier.

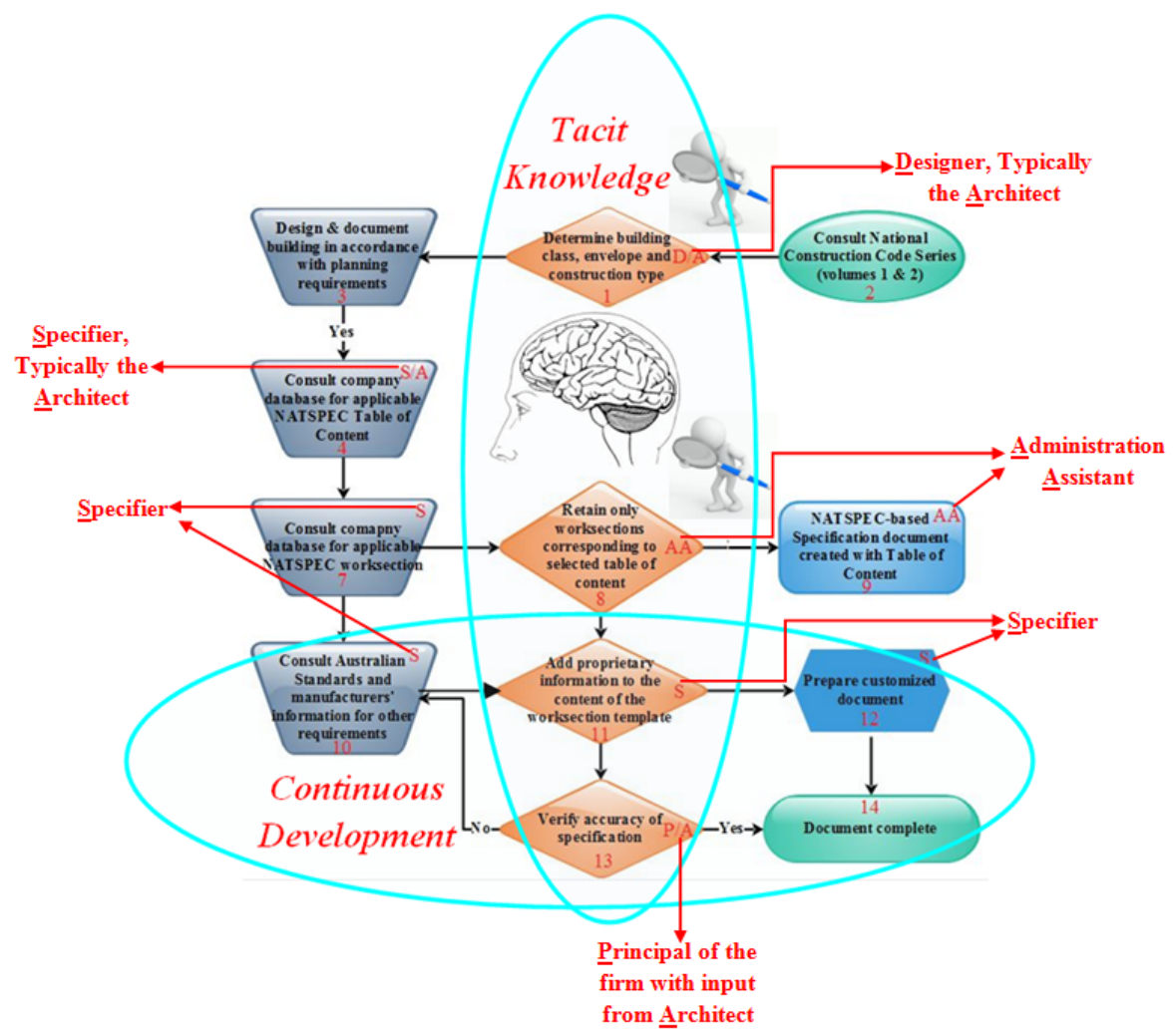

Figure 2. Transformed and encoded workflow for the creation of traditional specifications 
The following symbols illustrate the interpretations of the parameters captured in the workflow:
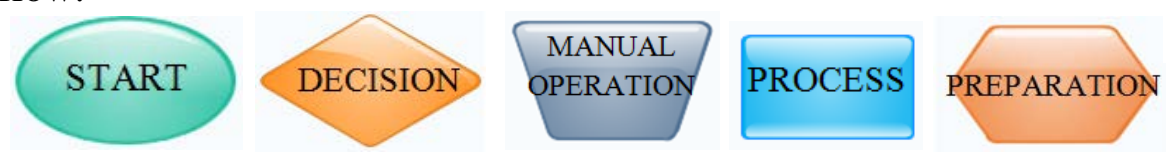

TERMINATOR

With the exception of component 14 (left un-coded based on its status as the final outcome), 'Actors' were assigned to all but two of the components in the workflow. The initial deduction of this outcome was that the unassigned components could potentially undergo automation in some form. However, upon further discussion with the Specifier, it was established that, with the right technological tool, all the components represented in the workflow are capable of automation. Moreover, five active roles in the specification process were identified, namely: the Specifier, the Designer, the Architect, Administrative Assistants and the Principal (or Owner).

Flow

Upon successful implementation of the codes, further review of the literature to investigate other representations of the specification writing process was undertaken. The body of literature shows evidence that the specification process diagram by the National Building Specification System of Australia (NATSPEC) (NATSPEC, 2013 ${ }^{\mathrm{a}}$ ) (see Figure 3) is the most illustrative and relevant to this research. The resulting comparisons between both workflows led to the identification of a flow gap in the existing literature.

The process of specification is too complicated to be depicted linearly as such a description would not effectively capture the intricacies of the decision-making process with which Specifiers are faced in the production of a specification document. The convoluted manner in which traditional specifications are produced can be optimised by creating a flow between the information nodes involved in the production of specification documents. For instance, Specifiers make references to documents (emails, phone calls, building codes, national standards, etc.) from professionals within their employing organisation who may affect or be impacted by the outcomes of the final document. Many of these documents can be embedded at specific points within the nodes depicted in the transformed workflow.

Value: Development and critique of a specification document

Taking cognisance of the central role of a Specifier to the production of specification documents, the process of specifying depends on the inputs and decisions of other Actors within the organisation. While this dependency is not fully captured in traditional representations of the specification process (Figure 3), the transformed workflow created from the participant observation clearly shows the dependencies (Figure 2). 


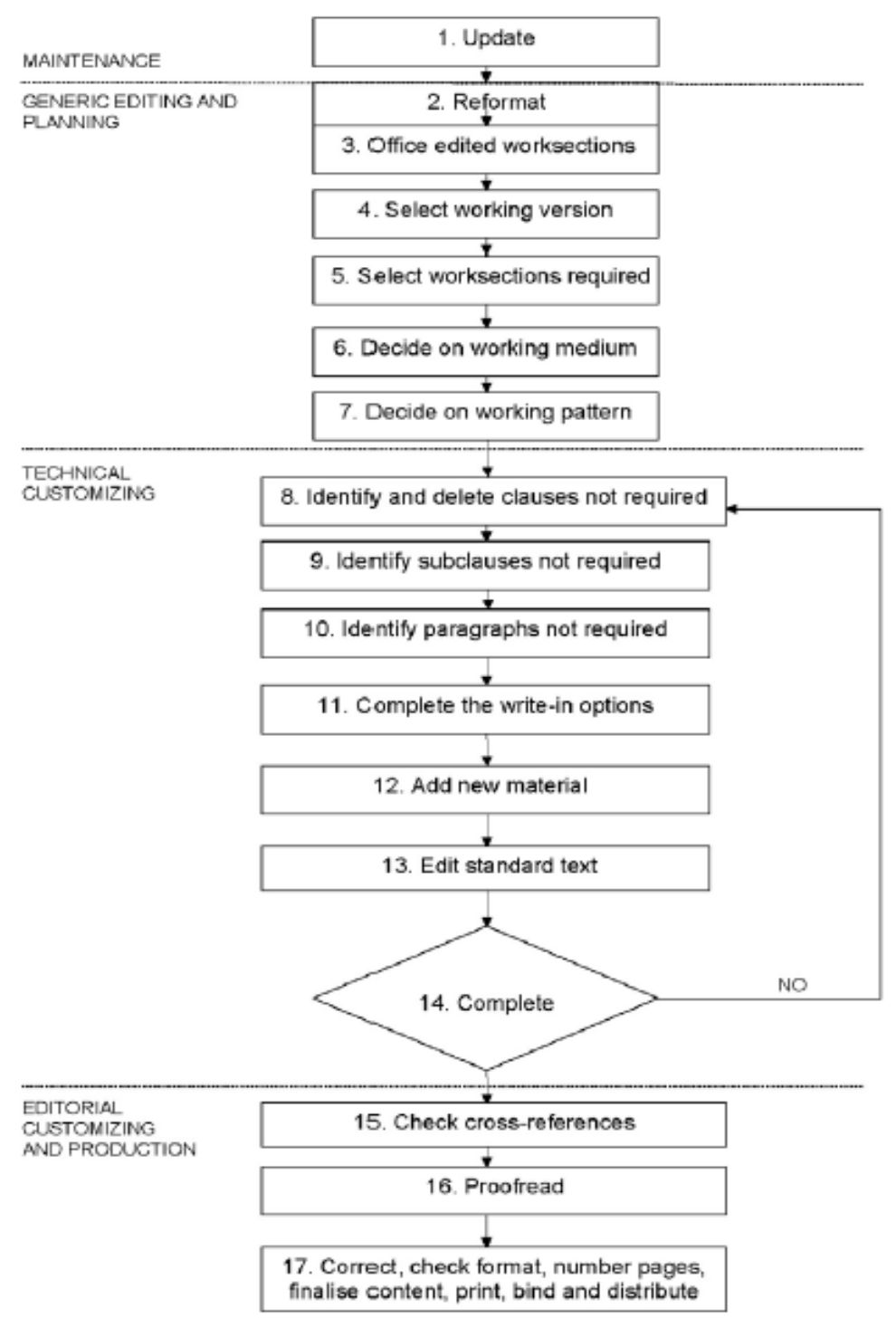

Figure 3. The NATSPEC Specification Writing Process (NATSPEC, 2013a)

Consequent upon the diagramming outcome of participant observation therefore, it is evident that key distinctions of this research from prior studies by Emmitt (2001) and NATSPEC $\left(2013^{\mathrm{a}}\right)$ are the development of a non-linear mapping of the specification process and the assignment of process actors. Thus, to develop the requisite knowledge and skills in undertaking in-depth investigation of construction specifications and to test the validity of the transformed specification workflow, a simple construction project within easy reach of the researching organisation was selected.

The Ekobode project is an eight-unit apartment building in the Gold-Coast area of Queensland (Figure 4).

The building was selected as a case-study for specification based on its simplicity. Although the building construction process is normally preceded by the production of the specification document, construction on the Ekobode project had already commenced at the time of the research exercise. Consequently, to mitigate researcher bias, it was assumed that the production of the specification occurred prior to on site construction. To this end, a site visit was organised to enable the primary researcher gain a better appreciation of the outcome of the specification process. 


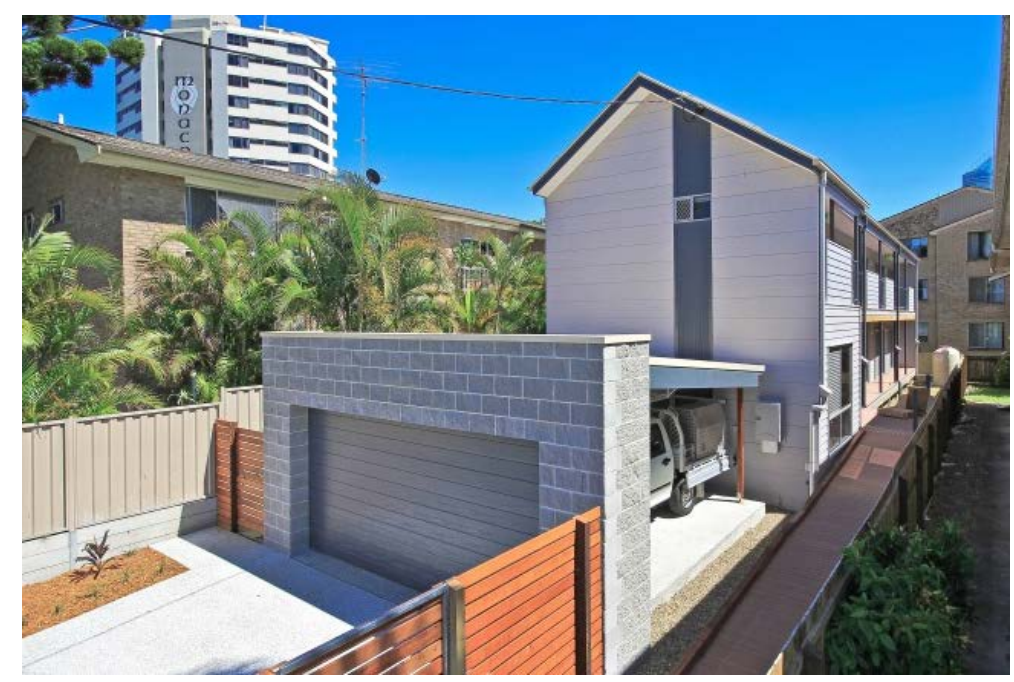

Figure 4. Elevation view of the Ekobode Project (Horizon Housing, 2013)

Thereafter, a specification document was developed based on the current NATSPEC specifications template in use by the observed participant at the sponsoring organisation. The benefit of the NATSPEC template is its provision of ready-made documents for use in specifying. Apart from the pre-populated worksections, the template typically has guidelines to assist in the decision making of the Specifier. However, some challenges were encountered in the development of the Ekobode specification, including:

- The need for tacit knowledge to complement the decision making that underscore most specification processes (as shown in the revised workflow)

- The need for a thorough understanding of construction drawings to which references are made so as to specify in line with the design of the building

- The constant need to reference other documents external to the specification document itself e.g. the National Construction Code Series (NCC) and the Australian Standards

- References to similar specification documents for a clearer understanding of the most practical specification clauses relevant to the project in question

- Considerable time expended in editing worksections to conform with the unique requirements of every project; requiring the deletion (waste) of whole worksections

These are considered the enablers for linking specification parameters to Building Information Models. Although this list is not exhaustive, it summarises some of the key practical problems encountered using current methods of specification even with the relative ease with which specification documents are produced as opposed to the thinking that influenced such specifications as the New Immigration Barracks (see the next section)

In summary, the experience gained in developing the construction specification document as a result of participant observation is highlighted by Nyiri (1992) who opines:

"One becomes an expert not simply by absorbing explicit knowledge of the type found in textbooks, but through experience, that is, through repeated trials, failing, succeeding, wasting time and effort ... getting to feel the problem, learning to go by the book and when to break the rules" (Nyiri, 1992, pp. 49-50).

\section{Critique of legacy specification methods}

Consequent upon the development of the Ekobode specification document, the specification of the Yungaba [New Immigration Baracks] at Kangaroos Point Brisbane, developed in August of 1885 (Department of Public Works, 1885) was investigated to differentiate 
between modern approaches to specification and dated methods. Specifically, the document served as a practical guide for understanding the evolution of construction specifications over a hundred year span. The following were some key findings from the exercise:

- Specifications have remained largely unchanged in terms of the overall content of the documents.

- Unlike the bulk of current specifications, owing to a proliferation of specification techniques and methods necessitating the creation of bodies like the Construction Specification Institute (CSI), the Yungaba Specification was very compact (short form specification).

- The contents of the Specification were arranged chronologically, by trade (e.g. Masons and Bricklayers, Carpenters and Joiners), consistent with the prevailing methodology of the era in which it was produced (Donaldson, 1860).

- The major difference between current and date methods of specifying is the documentation of specifications in digital formats and the wide-spread use of Specification templates. For the most part, the templates serve as guidelines to enable Specifiers make connections with other building documents such as: the Building Code of Australia (now called the National Construction Code) and the Australian Standards.

- Specifications are as much an integral part of construction contracts today as they were over a century ago.

The exercise served as practical instruction in verifying the accuracy of the body of literature regarding the evolution and standardisation of specifications in view of the challenges and the various methods of specifying that emerged in the post-world war II era (MasterFormat, 2004) in response to those challenges.

\section{Results}

The procedures that underpinned the final outcomes of the participant observation exercise were the discussions that led to development of the transformative workflows (see Figure 1 and Figure 2). In turn, the transformed workflow aided the identification of flow and value gaps. The results of the combined processes are as follows:

- The specification process is complex and non-linear. As such, attempts at integrating construction specifications and digital models must take into account the attribute of nonlinearity, factoring parameters, as shown in Figure 2 such as:

o interactions between the key players; Specifier, Architect, Designer, Principal, Administration Assistant

o the influence of external references; a Master Specification System, Australian Standards, various databases containing manufacturers' information, the National Construction Codes, planning requirements

- Construction specifications, in their finished forms, are the products of several 'Actors' whose contributions are reflected in the specification worksections and who are impacted by the final product

- A key requirement for producing construction specifications is tacit knowledge. Thus, specifications can leverage links to digital models for capturing such knowledge in a non-redundant way. However, considerations must be given to inexperienced Specifiers who benefit from guide notes embedded within the worksections of traditional specification templates and training provided in enabling such stakeholders gain the requisite knowledge for representing specification knowledge on digital modelling platforms. 
- There is a need to minimise Wastes (in time and effort), resulting from editing standard specification templates in order to tailor them to the requirements of each unique building project

\section{Conclusion}

Following a review of literature, this paper shows how the traditional process of construction specifications was transformed by means of participant observation. Flow and value gaps were identified and analyses of two specification documents (for a modern building and a facility aged over 100 years) resulted in the conclusion that current methods of specifying can be streamlined to benefit from linkages to digital models such as Building Information Models.

Thus, it has been shown that the philosophy of lean construction, through the TPV theory of construction, furnishes a rationale for revising current methods for representing the construction specification process and for producing specification documents.

\section{References}

Bertelsen, S., \& Koskela, L. (2002). Managing the three aspects of production in construction. Paper presented at the 10th Annual Conference in the Internatonal Group for Lean Construction, Gramado, Brazil.

Department of Public Works. (1885). Specification of New Immigration Barracks Kangaroo Point, Brisbane. Addenda to Specification.

DeWalt, K. M., \& DeWalt, B. R. (2010). Participant observation: A guide for fieldworkers (Second ed.). Plymouth, United Kingdom: Altamira Press.

Donaldson, T. L. (1860). Handbook of Specifications. London (cited in Rosen \& Regener 2005, p. 13).

Emmitt, S. (2001). Observing the act of specification. Design Studies, 22(5), 397-408.

Emmitt, S. (2006). Selection and specification of building products: Implications for design managers. Architectural Engineering and Design Management, 2(3), 176-186.

Goldbloom, J. (1992). Improving specifications. Civil Engineering, 62(9), 68.

Hartman, L. M. (2001).

Horizon Housing. (2013). Ekobode Project, Surfers Paradise. Retrieved 08 October, 2013, from

http://horizonhousing.com.au/index.php?com=com_properties\&category=5412\&action $=$ view\&itemid $=6$

Kalin, M., Weygant, R. S., Rosen, H. J., \& Regener, J. R. (2010). Construction Specifications Writing: Principles and Procedures (6th ed.). New Jersey: John Wiley \& Sons, Inc.

Koskela, L. (2000b). An exploration towards a production theory and its application to construction: VTT Technical Research Centre of Finland.

Marshall, C., \& Rossman, G. B. (1989). Designing qualitative research Sage. Newbury Park, CA: SAGE Publications.

MasterFormat. (2004). MasterFormat ${ }^{\mathrm{TM}} 2004$ Overview. Retrieved from http://www.technical-expressions.com/mf/spec-history/index.html website:

NATSPEC. $\left(2013^{\mathrm{a}}\right)$. Specification Writing NATSPEC Specification Word processing and Production (pp. 1-21). Sydney.

Nyiri, J. (1992). Tradition and practical knowledge.

Oppenheim, B. W., Murman, E. M., \& Secor, D. A. (2011). Lean enablers for systems engineering. Systems Engineering, 14(1), 29-55.

Singh-Gill, P. (2012). Application of value stream mapping to eliminate waste in an emergency room. Global Journal of Medical Research, 12(6). 